The article outlines a reconstruction of art education history. It has the aim that the attention in the field not only focuses on institutions, and their texts, to include infantile and teaching subjectivities in the reading/writing of history. It proposes a review of the field using the framework provided by the critical history of modernity, and suggests an interdisciplinary dialogue between: critical art history, critical studies and history of childhood, studies of popular culture, and contemporary art practice. Following this reconstructive perspective, the article includes the reading/writing of a history of the visual pedagogies for childhood education in the archive of the Catalan cultural journal Serra $\mathrm{d}^{\prime} \mathrm{Or}$, during the 60s and 70s. The practice of an intertextualization of the theories mentioned above with texts and images from this journal, and autobiographic narration, troubles the dominant temporal order in this archive, and the discourse on popular culture as a producer of desirable/undesirable childhoods.

Keywords: critical history, childhood subjectivities, popular culture. 


\section{Reconstruir las historias de la educación artística y de la infancia desde una política crítica de las representaciones en el arte, la cultura y la cotidianeidad}

Laura

TRAFÍ

El artículo propone una reconstrucción de la historia de la educación artística, con la finalidad de que la atención del campo se mueva del foco exclusivo en las instituciones y sus textos, e incluya también las subjetividades infantiles y docentes en la lectura/escritura de la historia. Se propone una revisión del campo desde los marcos de una historia crítica de la modernidad y se sugiere un diálogo interdisciplinar entre: la historia crítica del arte, los estudios críticos y la historia de la infancia, los estudios de cultura popular y las prácticas de arte contemporáneo. Siguiendo este planteamiento reconstructivo, se lee/escribe una historia de las pedagogías visuales para la educación de la infancia en el archivo de la revista cultural Serra d'Or durante el período de 1960-70 en Cataluña. A partir de intertextualizar la teoría mencionada, con textos e imágenes de la revista y el relato autobiográfico, se problematiza el orden temporal dominante en este archivo y el discurso en torno a la cultura popular como productora de infancias deseables/indeseables.

Palabras clave: historia crítica, subjetividades infantiles, cultura popular. 


\section{Leer/escribir la historia de la educación artística desde la modernidad crítica}

En los últimos diez años, en Catalunya y el resto del Estado Español ha habido un esfuerzo importante para una comprensión histórica del campo de la educación artística, motivado por las diferentes Jornadas de Historia de la Educación Artística coordinadas bianualmente, desde el año 1994, por el Dr. Fernando Hernández (Universitat de Barcelona). En este marco, diferentes investigadores han desarrollado un esfuerzo contextualizador de corrientes pedagógicas, teorías curriculares, leyes de educación, a través de utilizar herramientas provenientes de las historias sociales, culturales, feministas y/o orales. Con frecuencia, los análisis se han situado en el marco institucional de la escuela y en el marco académico de las teorías y sus textos. En esta línia, las investigaciones históricas realizadas hasta el momento vinculadas a la educación artística de la infancia nos han permitido contextualizar la emergencia del expresionismo como corriente pedagógica (años 40), su tardía llegada a España en el contexto de los movimientos de renovación pedagógica (años 60), la "naturalización curricular" de la expresión, como algo propio e intrínseco de la etapa de infantil a partir de la Ley de Educación (1970), y finalmente la psicologización de los formalismos modernistas en la LOGSE (1990) (HERNÁNDEZ, MOREJÓN, JUANOLA, 2001). Este esfuerzo nos ha sido útil para comprender los expresionismos y formalismos como construcciones históricas y no como instancias consustanciales a la infancia y al saber escolar de la educación artística

La emergencia del paradigma de la educación artística basada en la cultura visual parece que apunta a la necesidad de construir nuevas lecturas/escrituras de la historia de la educación artística que permitan incluir una perspectiva más amplia de las relaciones entre discursos visuales y subjetividades docentes e infantiles. Siguiendo este propósito, este articulo representa una parte de un trabajo de investigación que tiene como objetivo entender el texto histórico, como un lugar cultural para la participación, el diálogo y la inscripción de subjetividades. En esta dirección, pretendo llevar la escritura de la historia al ámbi- 
Reconstruir las historias de la educación artística y de la infancia desde una política crítica de las representaciones en el arte, la cultura y la cotidianeidad

to de la formación de educadoras de arte en la etapa de infantil para comprender cómo son histórica y culturalmente montados los sujetos infantiles y docentes en esta etapa educativa.

Hasta el momento el discurso histórico de los educadores artísticos se ha focalizado en los modelos aportados por las ciencias sociales y posiblemente no se ha dirigido suficiente atención a los procesos y estrategias de narración histórica aportados por el arte y las humanidades. Una parte de las prácticas artísticas contemporáneas proponen también modelos de investigación histórica. Existen proyectos artísticos de calidad teórica, estética y visual que dialogan con la historia desde dentro del campo visual, trabajando con procesos y políticas de representación, a través de formas y tácticas propias del conocimiento artístico, literario, fílmico. La visión del arte como proceso interpretativo y de producción de conocimiento desde dentro del texto artístico, se la debemos en parte a nociones postestructuralistas como la muerte del autor y el nacimiento del texto (BARTHES, 1977, 2001). Éstas contribuyeron a una crítica importante a la modernidad, centrada en desmantelar la separación entre teoría y práctica, encarnada por los roles diferenciados del crítico de arte y el artista. En tanto que el texto en oposición a la obra, es producido y vuelto a producir en diferentes prácticas de interpretación y "se lee sin inscripción del Padre", se convierte en "ese espacio social que no guarece a ningún lenguaje, exterior, ni permite que ningún sujeto de la enunciación pueda ser juez, maestro, analista, confesor, descifrador" ya sea el crítico o el artista (BARTHES, 2001, p. 170-174). Desde este contexto de debates situado en los 70, diferentes artistas de arte contemporáneo se adhieren a la crítica del autor, entendido como único originador de significado y a la unidad de la obra, delineada por Barthes. Conciben un tipo de práctica artística reflexiva, centrada en la producción de múltiples textualidades y preocupada por abrir un espacio de visión/lectura dirigido a los espectadores y a las espectadoras (KELLY, 2001). Son prácticas que, en definitiva, reestructuran el campo visual, a partir de hacernos ver el lugar social e histórico que ocupamos en el mismo y desestabilizan la posibilidad de una práctica ocularocentrista y de un dominio escoptofílico 
único de tipo atemporal. Las prácticas críticas y feministas del arte contemporáneo "enfatizan la lectura como parte de la producción en lugar de su substituto, y la lectura como algo crítico para comunidades de lectores/visualizadores previamente excluidos, y [en consecuencia] producen un sentido expandido de lo público" (POLLOCK, 2001, p. 18). Las prácticas de lectura y de visión se convierten en prácticas de desfetichización del objeto artístico, convirtiendo la lectura en una narrativa de memoria en la que el pasado puede ser reconocido, recuperado y reinterpretado desde cuestiones urgentes emergidas en el presente y cazadas al vuelo. La interpretación se convierte por consiguiente, en una práctica política de leer la historia a contrapelo (BENJAMIN, 1999).

Para leer/escribir esta historia a contrapelo precisamos reflexionar sobre los lugares desde los que hemos escrito las historias modernas de la educación artística. Aquí lugar hace referencia, como apunta De Certeau (1993), no sólo a la localización espacio-temporal de los acontecimientos o experiencias narradas, sino también al lugar de las teorías interpretativas de la historia. Desde esta perspectiva, las historias que hemos escrito se han visto poco afectadas por el carácter autoreflexivo que ha caracterizado a la historia crítica de la modernidad, en la que no sólo se ha tratado de rescatar aquellos relatos ignorados por la corriente dominante del modernismo, sino que también se ha procurado explicitar que "nuestras" historias son resultado y están limitadas por las teorías y los modelos históricos que utilizamos para narrarlas y compartirlas (Benjamin, 1999). ¿Por qué determinados textos y sujetos culturales han sido escogidos como documentos y testimonios de nuestra historia y otros no? A menudo la historia de la educación artística ha dejado fuera de su archivo los textos culturales del arte, la infancia y la vida cotidiana. Incorporar estos textos al archivo de la historia de la educación artística plantea la construcción de otros órdenes, otras temporalidades, nuevos significados. Con este objetivo, en la primera parte de este articulo quiero plantear una intersección de saberes que me permitan construir un lugar de escritura/lectura de la historia de la educación artística que problematice la relación entre los discursos 
Reconstruir las historias de la educación artística y de la infancia desde una política crítica de las representaciones en el arte, la cultura y la cotidianeidad

sobre la infancia en los que las que las educadoras de infantil inscriben sus subjetividades docentes en el presente, con la reconstrucción de sus autobiografías infantiles como sujetos formados en los contextos de culturas visuales en competencia. Estos saberes son: la historia crítica del arte y las prácticas de arte contemporáneo, los estudios e historias crítica de la infancia, los estudios de cultura popular. En esta línea, propongo incorporar en la escritura histórica de la educación artística una perspectiva crítica de la modernidad influenciada por el feminismo y el postestructuralismo, en la que se haga visible una relación reflexiva y retrospectiva entre la teorización de los posicionamientos subjetivos (del presente) y la comprensión de la historia (del pasado) como una tarea política de lectura/escritura, que reconoce -contrariamente a lo que ha planteado la modernidad dominante (high modernism) - que la historia está hecha de complejidades, contradicciones y diferentes temporalidades (POLLOCK, 2001).

\section{Inscribir las subjetividades docentes e infantiles en la historia de la educación artística modernista desde la historia crítica del arte y las prácticas de arte contemporáneo}

En otros lugares educadoras feministas como Pen Dalton (1998) han utilizado la crítica cultural al modernismo practicada por la historia y las prácticas artísticas feministas, para desvelar los límites en los discursos del arte, de la infancia y del saber que incorpora la perspectiva modernista, todavía dominante en la educación artística en la escuela infantil. Dalton afirma, que son precisamente los cambios epistemológicos introducidos por la historia crítica del arte, el psicoanálisis como teoría cultural y los estudios visuales los que pueden permitir a la educación artística una nueva lectura histórica del campo y en este sentido una transformación de sus sujetos y objetos.

La subjetividad y la visualidad llevan ya muchos años constituyendo temas permanentes en el debate cultural que se desarrolla en la historia del arte y en la teoría feminista. Ambos campos de conocimiento tienen implicaciones en los cambios en la teoría, la 
práctica y la crítica de las artes y en los cambios en las relaciones de poder entre hombres y mujeres. La educación artística precisa revisar su complicidad con los valores de la época culminante del modernismo y empezar a enfrentarse, a nivel profesional, con cuestiones que atañen a la subjetividad y al campo de visión (1998, p. 102).

De esta manera, la historia de la educación artística puede aprender de la historia feminista a crear otros lugares a través de la escritura/lectura; espacios para otras significaciones histórica, social, biográficamente situadas. Esto significa que la historia no siempre esté narrada, desde arriba, desde la academia, sino que los sujetos de la historia de la educación artística que comúnmente no han participado en su narración -a pesar de ser objetos de la misma-, puedan introducir sus voces en el relato; por ejemplo, las voces de las educadoras de infantil y los/las niños/as. Esta inscripción en la historia no significa un giro hacia un esencialismo autobiográfico, una manera de ponerse personal. Se trata contrariamente de vernos como señala Felman (1993), no como sujetos fijados en una biografía conocida, terminada y mistificada, sino como sujetos por definir, que rastrean, leen/escriben y construyen su texto biográfico a través de la lectura crítica de los textos culturales que nos han producido y nos producen como sujetos. En la misma dirección, Butler (2001) ha afirmado que el "yo" que leemos en un texto forma parte de una gramática que lo precede y lo ha puesto allí. Por consiguiente el "yo" siempre es opaco y relacional y el trabajo autobiográfico se centra en mostrar la dificultad de acceso al "yo". Por su parte, Pollock (1999) ha hablado del deseo de otras historias, que abran otras atracciones visuales, otros espacios psíquicos para imaginar la subjetividad, en los que las espectadoras puedan ser productoras de cultura y lectoras/escritoras de la historia.

En este contexto de problematización biográfica, las obras de arte son interrogadas para buscar inscripciones de gnero; entendido de nuevo no como un estilo especifico o categoría de Mujer ya fijada, sino como una posibilidad, una posición subjetiva por de-re-construir en la escritura del texto histórico. Dalton (2000) ha descrito cómo desde los márgenes del dis- 
Reconstruir las historias de la educación artística y de la infancia desde una política crítica de las representaciones en el arte, la cultura y la cotidianeidad

curso modernista, y desde posiciones entendidas cómo débiles, las prácticas estéticas feministas proyectan las disrupciones más efectivas de la modernidad hegemónica. Estos lugares a menudo han tenido que ver con lo doméstico, el cuidado, la crianza, la cultura popular para mujeres, aspectos todos ellos que tienen una clara vinculación con los lugares culturales y materiales de trabajo que ocupan a las educadoras de infantil y los/las niños/as. En este sentido, Dalton sostiene que estos textos culturales proporcionan tácticas para reimaginar la educación artística y leer/escribir otra historia de nuestro campo que implique una reconceptualización de los saberes, las estrategias y las subjetividades. Y, no sólo es importante reconstruir históricamente las subjetividades docentes, a partir de ensayar modos de inscripción de las educadoras en formación en los discursos históricos del arte y de la educación. En el contexto de la educación infantil es igualmente crucial aprender a reconstruir el discurso sobre las subjetividades infantiles, a partir de releer/rescribir las biografías de nuestra infancia. La utilización de las prácticas de arte contemporáneo que reflexionan sobre cómo los discursos visuales dominantes mistifican a la infancia, abstrayendo del campo de lo visible las condiciones materiales y cotidianas de vida de los niños y las niñas, pueden constituir un texto cultural desde el que leer/escribir nuestras autobiografías.

Desde las prácticas artísticas contemporáneas se producen visualidades y textualidades críticas que permiten una revisión, reconceptualización e inscripción histórica de las infancias. Utilizan los medios de la fotografía, el vídeo y la instalación expositiva para problematizar los procesos de idealización que dominan campos de representación como el álbum familiar, mostrando que las fotografías de nuestra infancia realizadas por otros, median nuestra memoria de esta etapa de la vida (SONTAG, 1977: HIGONNET, 1998). Aunque estos trabajos artísticos no siguen el formato académico de escritura, ciertamente contribuyen al discurso histórico de las subjetividades infantiles.

Beyond the Family Album (1979), de la artista inglesa Jo Spence, constituría un ejemplo de trabajo artístico e investigación histórica. En él se interelacionan la práctica artística de la 
fotografia, la cultura popular, el activismo feminista, la narración autobiográfica y la pedagogía, a través de problematizar las políticas de representación y autorepresentación que contiene este archivo de historia de la vida cotidiana. Se ha situado a Spence en las prácticas alternativas de reconceptualización de la fotografía que surgieron en Inglaterra a mediados de los setenta dirigidas a "desnaturalizar el realismo fotográfico y a rearticular la práctica artística y la práctica social" (RIBALTA, 2005 , p. 6). Su interés por la fotografía como medio popular de representación se identifica con una práctica fotográfica amateur; la fotografía de los trabajadores en la Europa de los años 30, y más tarde con el movimiento internacional de fotografía de los trabajadores y la liga internacional de cine en países como Holanda, Bélgica y Estados Unidos. En este movimiento, se planteaba que el cambio de las condiciones materiales de existencia pasaba también por tomar el control de las formas de (auto)representación y de "apropiación cotidiana de la imagen" (p.7). Spence estuvo interesada en reconstruir las formas en que las prácticas fotográficas dominantes (eg. la publicidad, la fotografía de estudio, el álbum familiar), visibilizaban o invisibilizaban al sujeto de clase, especialmente a la mujer trabajadora. Pero junto a diferentes colaboradores y grupos, también utilizó los medios precarios de la fotografía amateur, el collage, la secuenciación de diapositivas y otros, para producir visualidades críticas como forma de concienciación y de toma de control sobre las propias vidas y representaciones dentro de contextos de opresión. Todas estas cuestiones adoptan forma en el proyecto Beyond the Family Album:

[E]sos momentos visuales que existen [en el álbum familiar], "alegres", "serios", "amables", "desgraciados", pero siempre pasivos; esos momentos que sólo muestran una información superficial sobre mí, no dan ninguna indicación de las historias sociales, económicas y políticas más amplias de nuestra desagradable sociedad de clases. (Pero esto es lo normal en la mayoría de las familias, a las que se anima solo a fotografiar su ocio, lo que consumen, sus propiedades, y a mostrar la "armonía" de sus vidas). (...) Esta historia visual no es sobre mi "verdadero" yo. Es un conjunto de "construcciones visuales", realizadas empleando técnicas fotográficas, códigos y métodos de trabajo que se aplicaron sobre mí como 
Reconstruir las historias de la educación artística y de la infancia desde una política crítica de las representaciones en el arte, la cultura y la cotidianeidad

"tema", que ahora se puede decir que me representan. Es evidente que esos códigos no son "neutrales", sino que arrastran consigo ciertas formas aprendidas de leerlos y evaluarlos. Además, las palabras que he escrito en estas fotos pueden cambiar de manera en que, tradicionalemnte, pueden ser entendidas por otros. De esta forma, espero poder ganar una mayor comprensión del proceso de deconstrucción al que me he sometido, un proceso que resultó en el descubrimiento de que había negado mis raíces de clase obrera y mis antiguas empatías (SPENCE 1979: 2005, p. 174-5).

La visión de la infancia que emerge de este proyecto se basa en un trabajo retrospectivo, desde el presente y hacia el pasado para descubrir lo que ha quedado reprimido en la memoria que las fotos del álbum familiar tratan de fijar. En él se hacen evidentes las dificultades de escribir una historia de la infancia basada en las culturas y las experiencias de los niños y las niñas. Spence nos muestra cómo el álbum familiar no es un conjunto de "documentos" sobre nosotros como niños y/o niñas, sino un grupo de prácticas de representación visualmente construidas en un modelo dominante de clase media.

Los planteamientos de Spence y de buena parte del Feminismo, proponen que la práctica biográfica lleva a que las mujeres puedan explorar desde el interior de las prácticas de narrar (histórica, literaria y/o visualmente) las formas en cómo nuestras subjetividades han sido montadas. Esta cuestión se puede trasladar al contexto de formación de educadoras de infantil para preguntarnos: ¿De qué formas las imágenes de las propias infancias de las educadoras, centradas en la escuela pero también en la vida cotidiana, median en la formación de discursos sobre la infancia, la escuela, la subjetividad docente? ¿Cómo podemos transformar estas imágenes en narrativas visuales disruptivas de discursos normativos que fijan la infancia, la escuela, la subjetividad docente?

\section{La problematización de la infancia como sujeto/objeto histórico por parte de los estudios e historias críticas de la infancia}

También en los estudios y las historias de la infancia se han utilizado los marcos críticos de la modernidad para desmante- 
lar los saberes que han regulado las subjetividades infantiles, dominadas por los modelos racionalistas y universalizadores de la pediatría, la psicología, la pedagogía. Como ha señalado Kincheloe (2002, p. 76):

Con bastante frecuencia esta literatura ha estado satisfecha de dejar la definición de la infancia fuera de toda discusión y de separarla de fuerzas sociales más amplias. De este modo, a lo largo de varias décadas la infancia ha sido vista como "nosocial" o "presocial", más como la provincia de los psicólogos del desarrollo con sus descripciones universalizadoras de las fases "normales". Estas aproximaciones, a pesar de tener buenas intenciones, no han servido a los intereses de los niños y de las niñas, ni de aquéllos que tratan de ayudarlos. Al subestimar una apreciación de la diversidad y complejidad de la infancia, estos puntos de vista a menudo han equiparado la diferencia con la deficiencia y la construcción sociocultural con "lo natural".

Estas perspectivas críticas han mostrado cómo la función del saber especializado de la infancia es la de regular al sujeto niño y sus cuidadores adultos no-especialistas. La infancia es, por consiguiente, un lugar subjetivo diferenciado, que emerge y toma sentido formando parte de los mitos evolucionistas y de futuro en los que se funda la cultura moderna y su proyecto racionalista. Como ha señalado la historiadora de la infancia Egle Bechi (2005), en los textos de las pedagogías modernas se nos presenta a una infancia bajo un relato común, en el que el adulto se localiza como agente narrativo y el niño o la niña aparece en tercera persona, como objeto de la narración:

[C] uando el adulto habla del niño, lo hace casi siempre explicando cómo lo acompaña y lo guía en su existencia. Lo considera en fase de construcción, en un camino hacia la edad adulta, en un viaje que necesita del adulto para poderse llevar a cabo, y que reconoce en el adulto su meta irrenunciable. También bajo esta perspectiva, el niño parece existir fuera de sí, para el otro, para llegar a ser aquel otro -el adulto-, que se perfila como el terminus ad quem obligado a su destino. Si se detiene antes, muere, es "diferente", sufre una interrupción en su desarrollo, sale o se sitúa en el margen de la condición de infancia, para después ser localizado en otras categorías (2005, p. 33). 
Reconstruir las historias de la educación artística y de la infancia desde una política crítica de las representaciones en el arte, la cultura y la cotidianeidad

Según Bechi, la tarea de la historiadora de la infancia que se enfrenta con los textos de las psicologías y pedagogías del yo, es la de llevar a cabo una des-pedagogizacin provisional, del niño/a que se representa. Es decir, liberar al niño/a de los límites que los adultos le han impuesto, describir a la infancia no sólo como parte de un orden educativo que supuestamente le ayuda a sobrevivir, sino analizarla como parte de un orden discursivo que incorpora relaciones de saber-poder y formas de categorización históricamente construidas que conforman recorridos sociales y modelos de institucionalización y disciplinación. De esta manera, la des-pedagogización tendría como finalidad entender al niño o la niña como productor cultural y social, como constructor original de universos sociales compartidos en comunidades infantiles, de adultos y mixtas. Obviamente, en historiografia este ejercicio no comporta un retorno celebratorio a la libre expresión como algo consustancialmente infantil. Más bien es una oportunidad para construir la infancia como sujeto y objeto histórico, en un diálogo que al mismo tiempo permite repensar las formas de hacer historia, situando la relevancia los modos que utilizamos los textos y documentos históricos sobre y de la infancia, entendiéndolos no cómo un reflejo realista de una infancia, sino como discursos textuales y visuales que tienen que ser interrogados y analizados desde nuevas perspectivas. Es preciso introducir en la historia, este ejercicio que es de naturaleza teórica para poner en evidencia los vacíos testimoniales, documentales, archivísticos frente a los cuales nos enfrentamos cuando leemos/escribimos historias de la infancia.

\section{Las vinculaciones entre los estudios de cultura popular, los estudios críticos de la infancia y la modernidad crítica}

El proyecto cultural que las pedagogías modernas divisan para la infancia, puede leerse también desde la oposición entre alta cultura y cultura popular, en la que la inocencia, la bondad, la pureza del niño y la niña estará en el lado de la alta cul- 
tura, (la escolarización basada en el libro y la lectura de textos dirigidos a la infancia y su formación moral como ciudadanos) y la corrupción de su alma estará al lado de la cultura popular, los comics, la televisión, el materialismo comercial (BUCKHINGHAM, 2002).

La oposición entre alta cultura y cultura popular ha sido típica en las distribuciones del saber-poder específicas de las modernidades occidentales de postguerra vinculadas también a la literatura y al arte (BURGUIN, 1996). Esta oposición, como ha señalado en otro contexto Pollock (1996), representa dos piezas constituyentes de la economía simbólica capitalista y patriarcal. A través de la alta cultura se está representando un modelo masculino de autoafirmación individual caracterizado por la determinación, el esfuerzo, la superación, mientras que a través de la cultura popular se representa lo que carece de todas estas cosas, lo femenino, superficial, materialista, trivial y de moral dudosa. La educación artística y la historia del arte modernista han hecho que este modelo subjetivo sea encarnado por la figura del artista de vanguardia, y han traducido un alter ego del mismo en la figura del niño que "se expresa libremente"; un "pequeño" individuo masculino occidental moderno librepensante situado del lado de la alta cultura (DALTON, 1998). En el otro lado del binomio modernista, la cultura popular está representada por la estrella de cine mujer o tropo falocéntrico del puro espectáculo y el entretenimiento visual, la perfección de una superficie blanca y lustrosa, y la peligrosidad de lo desconocido que puede poner en jaque el orden cultural (POLLOCK, 1996). Del mismo modo en la separación entre educación /cultura popular, el estereotipo de la niña inocente, rubia, con ojos azules, bien vestida, vulnerable y que recibe protección adulta domina el universo de la cultura popular. Esta es una elección deliberada situada en una posición de género, clase y raza exclusivos. La tensión entre inocencia y sexualización explícita en la representación de la niña, es de difícil encaje en la figura eminentemente inocente y masculina del nio natural, que imaginan las pedagogías modernas (WALKERDINE, 1997).

Pocos estudios históricos han abordado la reconstrucción 
Reconstruir las historias de la educación artística y de la infancia desde una política crítica de las representaciones en el arte, la cultura y la cotidianeidad

de los procesos de consumo y los placeres visuales de la cultura popular por parte de los más pequeños. Esta carencia, refuerza la idea de Bechi, previamente subrayada, sobre la falta de documentos en los que se registren y se reconozcan las culturas de la infancia y los niños y las niñas como sujetos y objetos de la historia. También se identifica con la crítica a las pedagogías centradas en el niño de los estudios críticos de la infancia, en la que se postula...

...que nuestro conocimiento de los niños y lo que es mejor para ellos y ellas ha resultado en el silenciamiento de voces de personas humanas diferentes a las nuestras. Las voces del "conocimiento silencioso" son aquellas de los niños reales con los que trabajamos y que viven vidas reales en lugares que no concebimos, que muestran fuerzas y comprensiones con las que no hemos soñado y que construyen conocimientos que desafiarían los límites de nuestros propios mundos. (CANNELLA, 1997, p. 3).

No es posible concebir una historia de la educación artística en el cambio actual hacia la cultura visual, en la que no cuestionemos cómo nuestro campo se ha construido históricamente situándose de manera repetida en uno de los lados de la oposición entre alta cultura y cultura popular, y cómo esto ha significado dejar fuera de los límites de lo educativo, artístico y estético importantes culturas visuales y posiciones subjetivas de la infancia.

\section{La problematización de las pedagogías visuales en el archivo de Serra d'Or desde la inscripción biográfica}

Mi primer intento de reconstruir la historia de la educación artística desde el diálogo de saberes descrito hasta este punto se ha situado en el contexto de la cultura catalana durante el tardofranquismo, e incluye los años que van de 1960 a 1975. Este es un periodo caracterizado por ser el final de un régimen dictatorial que duró cuatro décadas y por la emergencia de la primera revista cultural en catalán, Serra dOr, después de treinta años de prohibición de las manifestaciones publicas en esta lengua. Al mismo tiempo, los seis últimos (1969-1975) coinciden con mi primera infancia como alumna de la escuela infantil 
y como consumidora de cultura visual popular.

Serra dOr se empezó a publicar en el año 1959 en Barcelona bajo un ambiente de excepcionalidad. La revista pudo salir a la luz, por estar supuestamente bajo control editoral de la Abadía de Montserrat, un importante enclave de la iglesia católica en Catalunya. La mediación eclesiástica sirvió para negociar este espacio de práctica cultural con el Régimen, algo que la intelectualidad catalana progresista no hubiese logrado de manera autónoma. Serra dOr se convirtió en testimonio de un tiempo, representó un lugar de encuentro cultural e ideológico y de oposición a la dictadura franquista, en un esfuerzo por poner a la cultura catalana junto a las manifestaciones de la modernidad cultural de la Guerra Fría, persiguiendo una alta calidad editorial y temática, buscando lo que se ha venido a llamar la construcción de un canon de intelectualidad resistente (FERRÉ, 2000). En la época de los 60-70, hasta la llegada de la democracia en 1975, no se incluirán en Serra dOr artículos que enuncien sin ambages una crítica al Régimen. La disidencia se introducirá siempre de manera indirecta, a través de la reivindicación y difusión de escritores, cineastas, artistas visuales, músicos, arquitectos, críticos culturales, científicos a nivel local, pero también internacional que fueran intelectual, social y políticamente avanzados. El discurso de progreso, modernidad y cosmopolitismo cultural se situa en oposición a la visión única, unitaria y folclorista de la cultura, basada en promover la unidad de los pueblos de España.

Como parte de este proyecto de construir un sentido de la catalanidad que pasaba por una identificación con la alta cultura, en Serra dOr se puso una especial atención para informar a sus lectores adultos sobre la educación que debían recibir los niños y las niñas para convertirse en ciudadanos catalanes librepensantes, culminadores de este proyecto cultural. Esta visión de la infancia y la educación no sólo tendrá influencia en la nueva Ley General de Educación de 1970, sino que socialmente configurará un discurso en el que se establecerán los límites sobre una infancia deseable/indeseable. 
Reconstruir las historias de la educación artística y de la infancia desde una política crítica de las representaciones en el arte, la cultura y la cotidianeidad

\section{La construcción de un modelo de infancia deseable desde el espacio diferenciado de la literatura infantil}

Cuando a inicios del 2000 me fui a la hemeroteca de mi universidad a consultar el archivo de Serra dOr tenía como objetivo conocer cómo el crítico de arte Alexandre Cirici, había formado y dispersado un discurso sobre la cultura y el arte de la modernidad en un contexto histórico de dictadura y cómo este discurso había contribuido a normalizar una relación entre la historia del arte catalán y la historia de las vanguardias y el arte de postguerra en el terreno internacional. Jusdanis (1991) ha señalado que en las modernidades tardías -como sería el caso de la modernidad catalana de los 60-70 los escritores, pero también los artistas visuales, se convierten en modelos culturales de individualidad que sirven en la construcción de un sentido de identidad nacional y en la invención de un canon literario y/o artístico que la refleja y la transmite.

La sorpresa fue no sólo encontrarme con un modelo cultural y nacional vinculado a la alta cultura adulta, también descubrí una defensa y promoción de una alta cultura para la infancia, algo que llamaba la atención en una revista cultural para adultos. Descubrí que Serra dOr era uno de los espacios culturales desde los que se difundía activamente la filosofía de la renovación pedagógica, a través de plantear un visión cultural de la educación que traspasaba la escuela y se vinculaba a la familia y al tiempo de ocio. También, en el contexto de cambios vinculado a la Ley General de Educación (1970) la revista fomentó el debate y dirigió una crítica importante al modelo de las escuelas nacionales y una defensa al acceso a la educación para todos los niños y niñas. Igualmente, la revista incorporó una visión de la educación artística que introducía críticas al modelo de la escuela franquista. Romà Vallés un artista vinculado la pintura de postguerra catalana, escribe un artículo defendiendo la vigencia de las ideas de la libre expresión y del arte infantil de Herbert Read de los 40 en el contexto de la educación en Cataluña en los 60. Establece conexiones de manera indirecta entre el contexto opresivo de las dictaduras y la guer- 
ra en Europa, al cual había dado respuesta los planteamientos de la estética humanista de Read, con el contexto de la España de aquel momento. Las teorías de la autoexpresión sirvieron a Vallés para criticar el modelo educativo basado en la copia y la reproducción, como propio de una visión opresiva y reproductiva de la educación artística (VALLÉS, 1960).

Serra dOr és eminentemente una revista de cultura literaria y la construcción del modelo de niño/a ideal se aprecia más repetidamente en la definición del niño/a lector/a, que en relación al niño/a artista. La lectura por parte de los niños y niñas se presenta como un proyecto civilizatorio que ocurre bajo responsabilidad y supervisión adulta. Si este proyecto fracasa, si el/la niño/a no toma el gusto por la gran literatura en el último estadio de este proceso, éste/a quedará fuera del territorio de la CULTURA y del proyecto reflexivo, crítico, pedagógico que ésta incorpora. Estas argumentaciones se aprecian en la entrevista a Marta Mata (FAULÍ, 1967). En aquel momento Mata era una de las líderes de la renovación pedagógica, autora de libros infantiles, supervisora de colecciones en la editorial La Galera y una de las responsables de la revista Cavall Fort; por consiguiente, alguien muy implicado en el impulso de la literatura infantil en catalán:

El pequeño pide al mayor, primeramente, que le muestre un libro bonito, que le dibuje libros para él, que se los escriba, que se los escoja y le ayude a comentarlos y después a escogerlos; llegará un momento en el que adustamente pedirá que todo el mundo le deje tranquilo (y tendremos que hacerlo con mucha discreción) y finalmente, podremos hablar con él de libros de tú a tú, incluso puede que nos recomiende alguno. Esto sucederá, si todo ha ido bien, hacia los dieciséis años en general, edad en la cual nos parece que podemos considerar adulto a un lector, pero, naturalmente, esto no se podrá hacer, si hemos dado mala literatura a nuestros hijos. (FAULí, 1967, p. 76)

El modelo cultural de decadencia moderna que otros intelectuales modernistas habían pronosticado en el arte y la literatura adulta debido a la amenaza de la cultura popular, aquí lo vemos trasladado a la cultura de la infancia. En la cita previa se pueden apreciar todos esos lugares comunes de la moder- 
Reconstruir las historias de la educación artística y de la infancia desde una política crítica de las representaciones en el arte, la cultura y la cotidianeidad

nidad dominante, en los que se incluye: una visión primitivista del niño como persona por formar, mezclada con cuestiones de aprendizaje por descubrimiento, pedagogía centrada en el niño, un modelo lector evolutivo y el canon cultural de la gran literatura como estadio superior del mismo. De hecho, la revista tenía una sección dedicada exclusivamente a presentar, reseñar y establecer el nivel de calidad de libros infantiles y juveniles de reciente publicación. Aurora Díaz-Plaja, la responsable de esta sección, valoraba más positivamente los formatos cultos de los cuentos tradicionales, con ediciones modernizadas y traducciones al catalán a cargo de escritores de renombre, que otros formatos más populares y de más amplia difusión como los tebeos. La década de los 60-70, va a ser un momento de explosión editorial para ambos tipos de publicaciones.

Recuerdo que los libros infantiles que más consumí y que con mayor interés leí eran precisamente los tebeos que eran altamente cuestionados en Serra dOr. En un artículo dedicado a la revista infantil Cavall Fort, Faulí (1966, p. 52) afirmaba lo siguiente: "Los calvos, las suegras, las solteronas, las conferencias, los sabios, los judíos, los negros y tantos otros lugares comunes no encuentran lugar en Cavall Fort. Ningún chiste puede incluir aspectos contrarios a la caridad". Unas palabras que indirectamente aludían al tipo de cómics que publicaba semanalmente la editorial Bruguera, un fenómeno de masas en la época de postguerra, que seguía el estilo cómico y esperpéntico del sainete y la comedia de situaciones y que leyeron miles de niños y niñas como yo a través de generaciones. Como ha señalado Walkerdine (1997), la cultura popular es un lugar de negociaciones complejas de la subjetividad, en el que se interseccionan las historias que consumimos, con expectativas personales silenciadas y los discursos hegemónicos de la subjetividad. En consecuencia, la lectura resultante de un texto específico de cultura popular no sólo tiene que ver con el objeto en sí, sino contrariamente con otros discursos y prácticas culturales vinculados a otras partes de nuestras vidas que podemos relacionar, proyectar y reconstruir en el texto que leemos. En este sentido, leer/ver estereotipos culturales en una revista cómica, no necesariamente tiene que significar que la única posible re- 
lación con los mismos sea una imitación irracional e irreflexiva. De nuevo, esta visión, corresponde a una mirada al niño y a la niña de la renovación pedagógica como un no-sujeto cuando está fuera del control adulto. También muestra, cómo la cultura popular infantil puede funcionar como un espacio de proyección de miedos y mecanismos de defensa frente a un posible un fracaso del proyecto ilustrado y modernizador de catalanidad.

El carácter no educativo de los tebeos o de la TV, era una afirmación sostenida en diferentes espacios de la revista, entre los que se incluían las cartas de los lectores, hecho que pone en evidencia la identificación de la audiencia con la línea cultural e ideológica de la revista. En la mencionada entrevista, Mata criticó explícitamente los tebeos de Tintn, cuya publicación en Catalán data también de este momento:

Se trata de un género híbrido, de imagen y texto hablado, que llamamos "cómic" o "tebeo". En el caso de Tintin, la extensión, la temàtica y la encuadernación han hecho que a menudo lo hayamos confundido con un libro (...) El lugar que me parece más adecuado para Tintín es la pequeña pantalla. Ahora bien, tratándose de libros, el niño se merece que le demos un dibujo y un texto literario muy superior al de cualquier "tebeo", Tintín incluido" (FAULí, 1967, p. 76).

En Serra dOr se habla permanentemente de lo bueno y lo malo para la educación de la infancia, pero nunca se oyen las voces concretas de los niños y las niñas, lectores de cómics como Tintn. La emergencia recientemente de relatos autobiográficos en los que se narra el carácter mediador de subjetividades infantiles de la cultura popular de los cómics y las historietas en los contextos de postguerra en Europa y España nos permite actualmente rescatar las voces y la memoria de aquella experiencia histórica (HOWE, 2000: GUIRAL, 2004). Uno de estos relatos lo ha firmado el escritor belga Luc Sante, y en él reconstruye su experiencia lectora de Tintín, como un espacio de lucha de significados públicos y personales, como un territorio de negociación y de trasgresión en el que se mezcla la ilustración y la racionalidad con el placer y la fantasía. 
Reconstruir las historias de la educación artística y de la infancia desde una política crítica de las representaciones en el arte, la cultura y la cotidianeidad

En relación a cualquier aspecto menos al visual es fácil desautorizar las simplificaciones de las series [de Tintín] que son el legado de una visión cómoda del colonialismo racionalizado. El estilo [de Hergé] hacía que el mundo fuese más maravillosamente accesible, sirviendo efectivamente como analogía de la misión del héroe: justamente porque Tintín, un simple chico, podía viajar a través del mundo y navegar por sus espacios obscuros y derrotar a sus opresores sin sucumbir a la corrupción, también tú podías confrontarte con la impresionante variedad del universo visual y comprender la simplicidad subyacente sin sacrificar la sensación de sorpresa. Éste era un elemento central del genio de Hergé: aliviar los miedos de su joven audiencia y convertirla en un goce sensual. (2002, p. 31)

Un aspecto que me parece realmente importante del relato de Sante, es que describe la existencia de una tensión entre lo visual y lo literario en los cómics de Tintin. Esto es importante, porque el tratamiento de lo visual presente en Serra dOr y en los comentarios de las escritoras y las ilustradoras de cuentos que aparecen en este momento, es que la ilustración es siempre subsidiaria del texto, debe guardar correspondencia con el mismo, debe ayudar a comprender el significado y los detalles de la historia contada. Sante ve la visualidad de los cómics de Tintn como otra textualidad que puede llegar a contradecir el texto literario o puede funcionar como un espacio de fantasía alternativo al mismo. Por estos motivos, sentí que sus reflexiones me ayudaban a comprender mejor el placer de leer aquellos cómics. Al mismo tiempo este campo de tensiones entre lo visual y lo literario delineado por Sante, se perfila como una cuestión prometedora en el trabajo con las educadoras de infantil de lectura/escritura histórica y autobiográfica de las culturas visuales populares de sus infancias.

\section{Problematizando el archivo de Serra d'Or y la producción de discursos visuales sobre las infancias deseables/indeseables}

Si problematizáramos el orden del archivo de Serra dOr, es decir el orden impuesto por las secciones en las que se organiza la propia revista -en las que se separa lo que es enunciable/ 
mostrable en la cultura adulta respecto a lo que es enunciable/ mostrable en la cultura infantil- podríamos descentrar y desuniversalizar las imagenes ideales y deseables de la infancia, con otras imágenes que permitieran imaginar la diferencia entre las infancias. Podríamos mostrar que tanto los contenidos, como las retóricas de la visualidad para la infancia, privilegian una posición de clase, genero, raza que se identifica con la clase media catalana blanca, que encuentra en el individuo masculino moderno su modelo de subjetividad ideal.

Como ha señalado Walkerdine (1998), una parte de los discursos visuales sobre la infancia de las pedagogías modernas que aparecen en la literatura educativa y psicopedagógica, se ha construido desde ciertas prácticas y retóricas de la fotografía. En éstas se representa al/la niño/a en sus espacios educativos haciendo las acciones individuales de aprendizaje, como leer, experimentar, manipular, descubrir, etc. Los/las niños/as actúan como si no existiera intervención o mediación de la cámara y del discurso fotográfico. Un ejemplo de esto lo constituirá la foto de portada del número de abril de 1968, en el que se incluye un monográfico de defensa del catalán como lengua de la educación escolar, en el contexto de elaboración de la Ley General de Educación. Para crear una visión positiva de este tema, la fotografía representa la idealización de una aula de niños y niñas blancos, de clase media, de unos 8 años de edad. La retórica visual muestra un entorno educativo con unos cuerpos ordenados hacia el saber, con luz natural, con unos pupitres de madera de pino barnizados de color miel, todos nuevos, agrupados con precisión y simetría en el espacio de aula y en el marco fotográfico, situados de cuatro en cuatro, entorno a la pizarra, dónde están escritas la fecha del día con letra redondeada y una frase que alude a una lección vinculada a los pronoms febles, una de las cuestiones gramaticales más características y complejas del catalán -Dnam el llibre, dna-mel. Los niños y las niñas miran todos atentos a los contenidos de la pizarra. A un lado de la misma hay un caballete, que sostiene un paisaje realizado en estilo infantil y unos botes de pintura con palos de pinceles que sobresalen; una alusión a otro espacio y a otro tiempo del aprendizaje. Vemos a los niños y a las niñas 
Reconstruir las historias de la educación artística y de la infancia desde una política crítica de las representaciones en el arte, la cultura y la cotidianeidad

aprendiendo solos, el maestro o la maestra ha quedado fuera del marco, a pesar de que la altura de lo que hay escrito en la pizarra funciona como índice de la presencia de un cuerpo de adulto. También la altura desde la que está tomada la imagen, por encima de las cabezas de los/las niños/as, alude a una encarnación adulta. Parece como si la fotografía fuese neutra, pues está capturada desde atrás como si los niños y las niñas no se dieran cuenta de la participación del fotógrafo y sus tareas escolares continuaran con toda normalidad. Sin embargo, todo es demasiado perfecto, nuevo, ordenado, silencioso, hay demasiados pocos niños en la imagen (¿también en el aula?), concretamente doce.

La fotografía de la infancia y de la escuela aparece en otros artículos de la revista. Un monográfico posterior, en el que se analiza la necesidad de una reforma técnica, pero también social de la escuela en el marco de la Ley General de Educación, está ilustrado por imágenes de entornos escolares que se presentan como no-ideales (BENACH et.al., 1970). El pie de la foto situada en la primera página del monográfico dice así: "En el Camp de la Bota, la imagen brutal de una escuela de suburbio" (1970, p. 21). En la fotografía previamente analizada, del aula ideal, el pie de foto consistía en la firma del autor, "Barceló", un fotógrafo bastante conocido en este periodo. La falta de explicitación de un contexto escolar específico la hace funcionar como una representación universal de la escuela, la infancia y el aprendizaje. Por el contrario, esta otra imagen (o imagen de los otros), está situada en un lugar histórico y geográfico, de la represión franquista, en el que se llevaron a cabo 1705 fusilamientos entre 1939 y 1952. Un no-lugar donde terminaba el núcleo urbano de Barcelona y empezaban los asentamientos informales de los desclasados de la ciudad, muchos de ellos gitanos. La imagen tiene en primer plano unos postes desde los que cuelga ropa clara de niño, en segundo plano vemos más hilos de tender con ropa de adulto negra, en tercer plano se distinguen unas barracas, de las cuales no se sabe cuál es la escuela y en último plano surge monumental la caserna militar, construida en el siglo XIX para hacer prácticas de artillería y tomada por el Ejercito Nacional como lugar 
de práctica del horror, precisamente porque se trataba de tierra de nadie. Podemos utilizar la crítica del documental social reformista, planteada por fotógrafos como Jo Spence o Allan Sekula, en los setenta para ver cómo ambas imágenes poseen problemas éticos, que consisten en no concebir la representación en términos discursivos y políticos, sino contrariamente como un reflejo de lo real.

[La tradición del documental social reformista] al estar basada en un modo de representación victimista y piadosa, que enmascaraba sus condiciones de producción, reproducía las desigualdades que denunciaba. ¿Cuál era la legitimidad ética del fotógrafo para imponer a quienes fotografiaba la imagen de víctimas de la sociedad, en general sin un pacto previo ni un compromiso posterior continuado tras tomar la imagen? (RIBALTA, 2005, p. 7)

Una mirada de clase media domina los medios de producción de imágenes ideales y no ideales de las infancias pedagógicas en Serra dOr. En la revista se construye un discurso visual sobre el otro cultural en el que se normaliza su situación de desfavorecido social, sin que se conozca cómo dicha posición social se ha producido. Esta presencia estereotipada del otro sólo aparece cuando la infancia es representada para los adultos, nunca en los textos dirigidos a la propia infancia, donde domina la visión feliz, pura e ideal de clase media.

¿Cómo afectaron los discursos visuales y textuales normalizadores de la infancia formulados en Serra dOr a la fijación de posiciones subjetivas, sociales, históricas en las vidas cotidianas de infancias específicas en los 60-70?

\section{Leer las pedagogías de la cultura popular de los 60-70 desde otras temporalidades y subjetividades}

En un intento de tratar de responder a la pregunta previa, en este apartado voy a proponer un orden temporal de largo término, que no dependa de establecer el corte con el pasado en los 60, para comprender el papel de lo popular en la representación y autorepresentación de las clases trabajadoras. También voy a sugerir un desorden documental que intertextualice las narrativas visuales de la alta cultura infantil con las imáge- 
Reconstruir las historias de la educación artística y de la infancia desde una política crítica de las representaciones en el arte, la cultura y la cotidianeidad

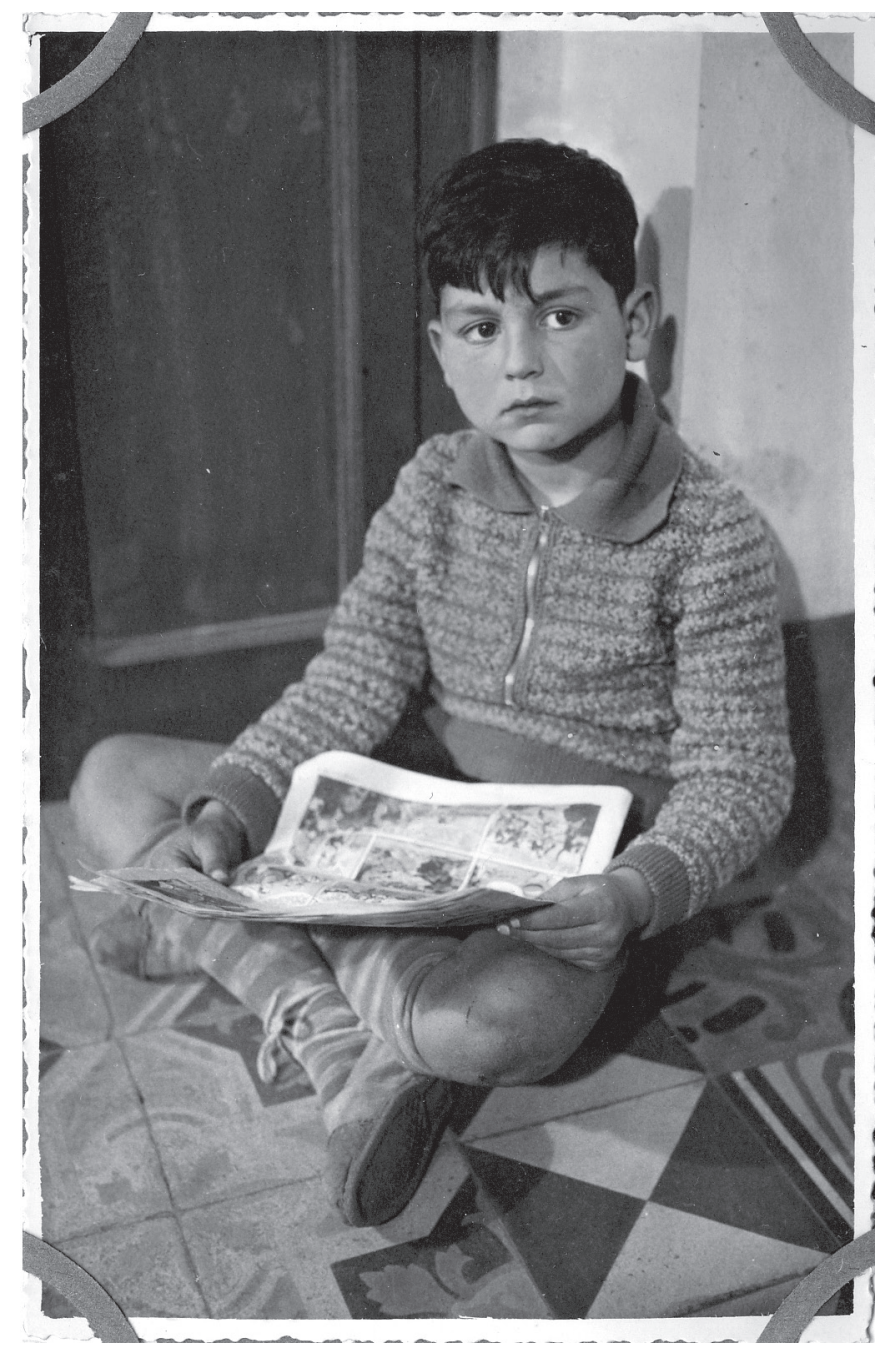

Figura 1 


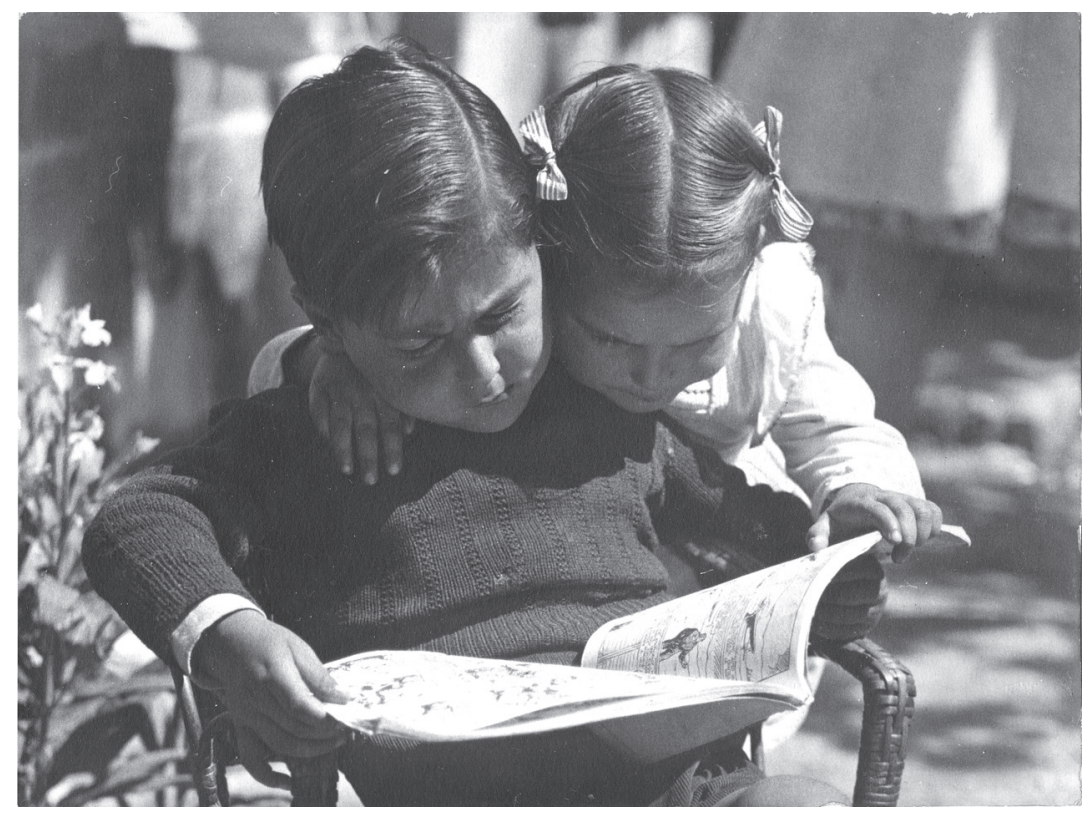

Figura 2

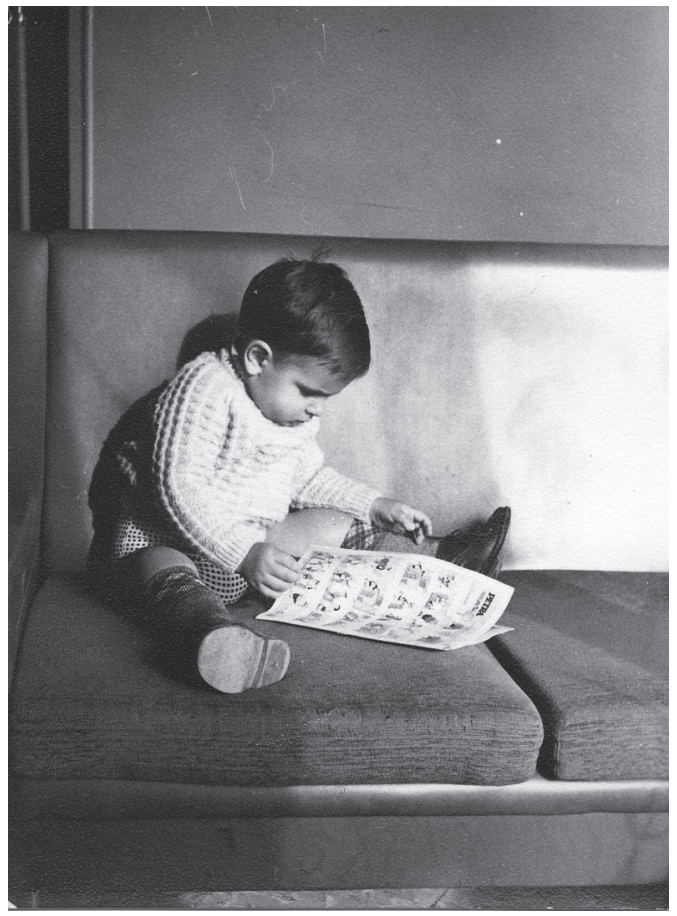

Figura 3 
Reconstruir las historias de la educación artística y de la infancia desde una política crítica de las representaciones en el arte, la cultura y la cotidianeidad

nes populares de la vida cotidiana, representadas en el álbum familiar. Empezaré primero con tres imágenes, todas ellas realizadas por mi abuelo, Faustí Trafí, fotógrafo amateur, primer miembro fundador de l'Agrupació Fotogràfica de Sant Adrià de Besòs. Las tres muestran tres generaciones de hombres de mi familia como niños lectores de tebeos.

La primera es una fotografía de mi tío Josep cuando era niño. Forma parte de un álbum que incluye varias fotografías en las que consta 1934 como el año de positivación; lo que hace pensar que la imagen debe girar en torno a esta fecha (fig. 1). Josep viste con las ropas de un niño de clase trabajadora: alpargatas con calcetines, pantalón corto de invierno y suéter de lana tejido a mano por la madre, Dolors. Está sentado en el suelo, junto a una puerta y sostiene un tebeo. El placer del fotógrafo por la imagen se aprecia no sólo por el hecho de construir un bonito encuadre de un uno de sus hijos en el espacio cotidiano del hogar, sino por el cuidado trabajo de colorear la imagen, inicialmente en blanco y negro, incluyendo los detalles del tebeo.

La segunda imagen es de otro de los hijos de Faustí, Pere, mi padre (fig. 2). Pere lee un tebeo con una amiga de la calle, según me explicó él mismo al volver a ver la foto. La imagen es de finales de los años 40, también coloreada a mano y Pere también lleva un suéter confeccionado en casa y el mismo peinado de pelo mojado con colonia y raya al lado. Hablando de ambas imágenes con mi padre, me explicó que mi abuelo no realizaba instantáneas, sino que más bien "preparaba" la escena, indicando al modelo cómo debía ponerse y hacia dónde debía mirar. Teniendo en cuenta la crítica del álbum familiar que propone la obra de Jo Spence, este tipo de contextualizaciones son interesantes para explicitar cómo los sujetos representados en la imagen son conscientes de la ficción y la parcialidad de la fotografía. En un intento de inscribir sus memorias de niño lector de tebeos, le pregunté a mi padre cual es el tebeo que aparece leyendo en la foto. Me respondió que no sabia el tebeo específico pues no recordaba el momento allí representado. Sin embargo, afirmó que por su grosor se trataba de un álbum, no de una revista semanal. Podía ser Jorge y Fernando, que era un 
cómic de aventuras en territorios coloniales de dos muchachos occidentales (como Tintín). También, me explicó que leía asiduamente Flash Gordon, Las aventuras de Roberto Alczar y Pedrn y la revista Pulgarcito, de la Editorial Bruguera.

La última fotografía es de inicios de los 70, en ella se representa a mi hermano Jordi con dos años de edad, mirando la página de detrás de la misma revista Pulgarcito, donde aparece el cómic de Petra criada para todo (fig. 3). Nuevamente vemos el mismo modelo de sujeto aseado y austero, con el mismo peinado, el suéter de lana, los calcetines. Aquí, la estilización y repetición de un modelo de sujeto lector que aparece en el resto de imágenes se hace muy evidente, en tanto en cuanto un niño de dos años que todavía lleva pañales no "lee" tebeos.

Aunque las ediciones regulares de Pulgarcito se remontan a 1947, el inicio de este "Periódico infantil de cuentos, historietas, aventuras y entretenimientos", data de 1921. El periodo de los años 60 y 70 coincide con una explosión comercial de la editorial, que es paralela a la emergencia y crecimiento de otras empresas editoriales para niños y niñas como hemos podido ver previamente (GUIRAL, 2004). Vidal y Santamaría (2004, p. 350) afirman que, "Junto a los seriales radiofónicos y las sesiones continuas de los cines de barrio, las revistas de cómic y los cuadernillos de aventuras eran el entretenimiento de las clases populares durante la postguerra". Por consiguiente, podríamos sostener que las tres fotografías parecen representar una relación de largo término (más de cuarenta años) del sujeto infantil con dos géneros de cultura popular. Por una parte, encontramos el género del humor esperpéntico dirigido a ironizar sobre de las dificultades y tensiones que caracterizaban la vida cotidiana de un país atrasado, necesitado, aislado del mundo (las viñetas de Forges y el semanario El Jueves constituirían ejemplos de continuidad de este género en la actualidad). Por otra parte, Pulgarcito también incluía el género de fantasía, ficción y aventura que fomentaba la evasión respecto a las realidades históricas, sociales, culturales. Estos elementos nos ayudan a afirmar que las criticas que autores y lectores practican en las páginas de Serra dOr aludiendo a publicaciones como Pulgarcito, así como el consecuente planteamiento de un cambio 
Reconstruir las historias de la educación artística y de la infancia desde una política crítica de las representaciones en el arte, la cultura y la cotidianeidad

radical hacia una cultura visual popular "más pedagógica", se realiza sin tener en cuenta que los vínculos con la cultura visual popular se construyen histórica y socialmente y están imbricados con las posiciones que históricamente ocupan los sujetos.

Siguiendo a Butler (2001), podemos sostener que la reiteración iconográfica a través de 40 años del niño lector de tebeos, produce una performance del género en la que el sujeto masculino de clase trabajadora utiliza la cultura popular y el ocio para (auto)representarse a través de un ego idealizado, como un sujeto civilizado, racional, heterosexual equiparable al sujeto abstracto y universal de la clase media blanca, reproduciendo de esta manera la normatividad de la matriz heterologocéntrica del patriarcado y el capitalismo. Por lo que afecta al patriarcado, vemos como la identificación desde lo popular con las imágenes del niño moderno ilustrado de las pedagogías modernas es eminentemente masculina. En algunos detalles materiales (la ropa, los entornos, los recursos materiales) podemos ver inscrita la diferencia de clase respecto al ideal burgués, pero la estructura de la diferencia sexual se encuentra intacta (DALTON, 1998: WALKERDINE, 1997). Recuerdo pasarme largos ratos de mi infancia leyendo las revistas Pulgarcito y Mortadelo que aparecían cada semana y que mi padre compraba y traía a casa para que mi hermano y yo las pudiéramos disfrutar. Sin embargo, no he encontrado ninguna imagen en el álbum familiar en la que reconocerme como lectora de estos textos de cultura popular y tengo muchas fotos que me representan recibiendo los cuidados de mi madre, jugando con muñecas y cocinas, vistiendo bonitos trajes feminizados y sonriendo a la cámara. El lenguaje con el que construimos culturalmente el género y su actuación y materialización en las relaciones de parentesco inscribe en nuestros cuerpos posiciones normativas de género. El álbum familiar las escenifica y trata de naturalizarlas en un relato mítico. En el caso del álbum de mi familia las niñas quedamos fuera de la producción lectora y se nos muestra vinculadas a otras prácticas que se entienden como propias de la feminidad: la identificación con la figura de la madre, el hogar y la satisfacción del placer visual del otro.

Por lo que afecta al capitalismo, las tres imágenes significan 
también por lo que han dejado fuera del campo visual y que define a los sujetos de mi familia como sujetos históricos: el trabajo. Como ha descrito Spence $(1972,2005$, p. 98-9) "cada una de las imágenes del álbum familiar es una negación de todo lo demás que podría estar en ese mismo álbum (...) [S]on una especie de velos que te ocultan el pasado. (...) Y siempre que tu historia se vuelve a contar a partir de estas fotografías este proceso de ocultación se refuerza". En este sentido, no existen prácticamente imágenes en el álbum familiar que aludan al tiempo dedicado a la producción ni a las condiciones de la misma, que ha definido el esquema temporal y espacial de la historia de familia. Más allá del entorno del hogar, no hay prácticamente imágenes que aludan a los espacios de tránsito y socialización entre la casa y la fábrica, entre el centro y la periferia industrial de la ciudad. Benjamin en sus "Tesis de filosofía de la historia" (1999) afirma que el capitalismo impone un sentido de la historia como progreso identificado con el continuum productivo y sostiene que solo es posible realizar una crítica a éste tiempo no-natural e impuesto desde fuera a partir de situarnos en los no-momentos, entendidos como prácticas disruptivas de parar la linealidad e introducir la memoria. Las prácticas de autorepresentación de Jo Spence como trabajadora en su relectura del álbum familiar tienen que ver con estas prácticas de fragmentar lo aparentemente lineal y coherente en su álbum, para hacer memoria y dejar constancia de las condiciones de producción y, de los significados e identidades de clase. En este sentido, Benjamin comprendía la revolución no tanto de manera utópica como un movimiento colectivo y sublimado que ocurre en una fase histórica específica situada en el futuro, sino con actos individuales vinculados a la vida cotidiana identificados con la máxima marxista de desfetichizar las mercancías para comprenderlas como objetos históricos repletos de pasado. Contrarias a cualquier acto de activismo político, estas tres fotos del álbum familiar están inscritas en un tiempo mítico situado fuera de la producción y la identidad de clase, precisamente porque no se encuentran conectadas con otras imágenes que muestren las tensiones entre la vida privada y el trabajo, entre los espacios y los tiempos. La posi- 
Reconstruir las historias de la educación artística y de la infancia desde una política crítica de las representaciones en el arte, la cultura y la cotidianeidad

bilidad de inscribir las lecturas, placeres, recuerdos vinculados a la lectura de tebeos, permite perturbar esta representación atemporal y mitificada y reconocer el espacio de ocio como un lugar de producción y en consecuencia como un espacio histórico. Sin embargo, este espacio ha sido victima de otras prácticas de borrado desde aquellas instancias que podían haber leído/ escrito a la infancia como productora de culturas. Esto se ve claramente en las prácticas editoriales de los 60-70 en Serra $d O r$, donde la noción de literatura infantil y de infancia lectora se presenta como una ideología de futuro y progreso, desestimando la densidad del pasado y estereotipando otras prácticas lectoras e identidades infantiles precedentes. Ésta es una posición que ha caracterizado muchas de las prácticas culturales que han determinado la transición hacia la democracia en estos últimos treinta años en España, que han evitando una puesta en marcha de la memoria colectiva en la que se pudiera revisar cómo las ruinas del pasado viven en las culturas cotidianas del presente, también en la infancia.

La intertextualización de éstas imágenes del ámbito personal cotidiano con los textos e imágenes públicas de Serra dOr y las teorías descritas en el artículo, nos permite argumentar que no es posible comprender el lugar que ocupa lo popular en las vidas de los niños y niñas de los 60-70, especialmente en situaciones de diferencia cultural, si sólo pensamos en la integración social en un modelo de desarrollo cultural normativo, vinculado a la alta cultura y/o a la cultura escolar. Este planteamiento sólo lleva a describir la relación de la infancia con la cultura popular en términos de carencia y mitifica el relato histórico. Tampoco es posible la comprensión, si conceptualizamos el éxito del aprendizaje cultural en términos de racionalidad y no podemos entender el placer y la fantasía como espacios de producción de identidades pedagógicas (docentes e infantiles). El diálogo con la cultura popular tiene que ver con la clase, el género, la raza y consiste en dinámicas psicosociales complejas, constituidas por sistemas de defensa, fantasías y expectativas, pero también por las condiciones materiales y sociales objetivas que definen la posición de género, clase y raza y sus posibilidades de transformación en la historia. Reconstruir la historia al 
tiempo que se reconstruye la propia biografía, en una práctica de escritura que permite incorporar diferentes textos y diferentes voces, abre la posibilidad de comprender tanto las dificultades y parcialidades de leer/escribir la historia de la educación artística, como la opacidad del yo en el texto. El discurso histórico no es lineal, está hecho de pliegues, de contradicciones y de diferentes temporalidades y es importante ensayar maneras que permitan leerlas/escribirlas, de forma que podamos poner en evidencia que hay partes del pasado que acaban apareciendo como irrepesentables e indecibles, poniendo de relevancia que nuestras subjetividades están todavía más fragmentadas y son más inaccesibles de lo que preveíamos al iniciar esta tarea.

\section{Conclusiones: ¿Cómo seguirr a partir de aquí?}

Quiero continuar este trabajo a partir de abrir un espacio para la investigación histórica en la formación de educadoras de la etapa de infantil en el contexto de la asignatura de Didáctica de las artes Plásticas. El trabajo vinculado a la reconstrucción del archivo de Serra dOr puede funcionar como un ejemplo de cómo utilizar los saberes de la historia feminista del arte, los estudios críticos de la infancia, la historia visual y las prácticas de arte contemporáneo para producir relatos que permitan comprender a través de la reconstrucción biográfica cómo hemos sido construidas como sujetos de la educación artística, en el contexto amplio de la cultura visual dentro y fuera de la escuela de un periodo histórico específico. En este trabajo es importante enseñar-aprender estrategias para una lectura/ escritura activa de la historia: La primera de estas estrategias debería centrarse en comprender la propia infancia no como un estado natural o universal, ni como un paraíso perdido, sino como una producción histórica. Describir, en definitiva, los límites qué constituyen una infancia ideal en los discursos pedagógicos de un determinado momento, y qué subjetividades y experiencias infantiles quedan fuera de esos límites. Una segunda estrategia se dirigiría a crear relaciones alternativas y perturbadoras con los archivos culturales que determinan el montaje de nuestras historias sociales y personales como niños/as, a partir 
Reconstruir las historias de la educación artística y de la infancia desde una política crítica de las representaciones en el arte, la cultura y la cotidianeidad

de crear relaciones inesperadas con textos e imágenes que posibilitan la emergencia de otros significados y la reconceptualización de nuestras subjetividades infantiles. Y finalmente, una tercera estrategia, estaría dirigida a ensayar la introducción de otras temporalidades en el orden dominante de la historia, como por ejemplo, tiempos que tengan que ver con aquello que no cambia de la historia y que a menudo dominan las prácticas de la vida cotidiana. Me encuentro actualmente trabajando con educadoras en formación de la etapa de infantil en las problemáticas de la escritura autobiográfica y la reconstrucción del álbum familiar en un contexto de formación, y a partir de cuestiones que llevan a explorar el papel de la cultura popular en la formación de las subjetividades infantiles. Espero poder escribir una continuación de este texto en un futuro cercano.

\section{Referencias}

BARTHES, R. The death of the author. En: HEATH, S. (ed.). Image, music, text. London: Fontana Press, 1977 (1968), p. 155-164.

BARTHES, R. De la obra al texto. En: WALLIS, B. Arte despus de la modernidad. Nuevos planteamientos en torno a la representacin. Madrid Akal 2001, (1971), p. 169-174.

$\mathrm{BECHI}, \mathrm{E}$. La historia de la infancia y sus necesidades de teoría. En: Coloquio de historia de la educación, XIII, de 29/06 a 01/07, 2005, Palacio de Miramar, Donostia. DÁVILA, P. \& NAYA, L. Ma . (cords.) La infancia en la historia: espacios y representaciones. Donostia: Erein, 2005, vol. 1, p. 21-38.

BENACH, J.-A. et.al. L'escola demà-passat. Reforma Técnica o reforma social?. Serra dOr, Barcelona, no 127, p. 21-32, abril 1970.

BENJAMIN, W. Thesis on the philosophi of History. En: ARENDT, H. (ed.). Illuminations. Londres: Pimlico, 1999 (1955), p. 245-255.

BUCKHINGHAM, D. Crecer en la era de los medios electrnicos. Madrid: Morata, 2002 (2000).

BURGUIN, V. Introduction. En: In/different spaces. Place and memory in 
visual culture. Berkeley: University of California Press, 1996, p. 1-38.

BUTLER, J. El gnero en disputa. El feminismo y la subversin de la identidad. Barcelona: Paidos, 2001.

CANNELLA, G. S. Deconstructing early childhood education. Social justice and revolution. New York: Peter Lang, 1997.

DALTON, P. The gendering of art education. modernism, identity and critical feminism. Buckingham: Open Unversity Press, 2001.

DALTON, P. Modernismo, educación artística y diferencia sexual. En: DEEPWELL, K. Nueva crtica feminista del arte. Estrategias crticas. Madrid: Cátedra, 1998 (1995), p. 91-102.

DE CERTEAU, M. La escritura de la historia. México D.F.: Universidad Iberoamericana 1993, (1978).

FAULí, J. Una hora amb la gent de Cavall Fort. Serra dOr, Barcelona, no 10, p. 103-4, octubre, 1966.

FAULí, J. Marta Mata parla de llibres per a nois i noies. Serra dOr, Barcelona, n4, p. 73-77, abrl 1967.

FELMAN, S. What does a Woman Want? Reading and Sexual Difference. Baltimore y Londres: John Hopkins University Press, 1993.

GUIRAL, A. Cuando los cmics se llamaban tebeos. La escuela Bruguera (1945-1963). Barcelona: El Jueves, 2004.

HERNÁNDEZ, F., MOREJÓN, L., JUANOLA, R. (cords..) Jornades d'història de l'educació artística, V, 20-21/02, 2003, Facultat de Belles Arts, Universitat de Barcelona, Facultat de Ciències de I'Educació, Universitat de Girona.. La perspectiva expressionista i els llibres de text per leducaci artstica. Barcelona: Impressions Belles Arts, 2003.

HIGONNET, A. Pictures of innocence. The history and crisis of ideal childhood. Londres: 1998.

HOWE, S. (ed.). Give our regards to atomsmashers! Writers on Comics. New York: Pantheon, 2004.

KELLY, M.. Contribuciones a una re-visión de la crítica moderna. En: WALLIS, Brian. Op. Cit. (1981), p. 87-103.

KINCHELOE, J. L. The complex politics of Mc Donald's and the new childhood: colonizing kidworld. En: CANNELLA, G. S. \& KINCHELOE J. L. (eds.). Kidworld. Childhood studies, global perspectives and education. New York: Peter Lang, 2002, p. 75-121.

POLLOCK, G. Killing men and dying women. A woman's touch in the cold zone of American painting in the 1950s. En: ORTON, Fred \& POLLOCK, Griselda. Avant-gardes and partisans reviewed. Manchester: Manchester University Press, 1996, p. 219-294. 
Reconstruir las historias de la educación artística y de la infancia desde una política crítica de las representaciones en el arte, la cultura y la cotidianeidad

POLLOCK, G. Differencing the canon. Feminist desire and the writing of arts histories. Londres y Nueva York: Routledge, 1999.

POLLOCK, G. Looking back to the future. Essays on art, life, and death. Ámsterdam: G+B, 2001.

ROBERTS, J. Entrevista con Jo Spence. En: RIBALTA, Jorge \& DENNET, Terry (eds.). Jo Spence Ms all de la imagen perfecta. Fotografa, subjetividad, antagonismo. Barcelona: MACBA, 2005 (1992), p. 88-103.

RIBALTA, J. Jo Spence Más allá de la imagen perfecta. Fotografía, subjetividad, antagonismo. En: RIBALTA, Jorge \& DENNET, Terry (eds.). Op. Cit., p. 6-15.

SANTE, L. The Clear Line. En: HOWE, Sean (ed.). Op. Cit., p. 24-32.

SPENCE, J. Más allá del álbum familiar. En: RIBALTA, Jorge \& DENNET, Terry (eds.). Op. Cit. (1979), p. 172-213.

SONTAG, S. On photography. Harmondsworth: Penguin, 1978.

VALLÉS, R. Importància i desenvolupament de I'Educacio per l'art. Serra dOr, Barcelona, no 3-4, p. 51-52, marzo-abril 1960.

VIDAL, J. \& SANTAMARÍA, C. La factoría de humor Bruguera. En: GUIRAL, A. Op. Cit., p. 350-353.

WALKERDINE, V. Daddys girl. Young girls and popular culture. Cambridge: Harvard University Press, 1997.

WALKERDINE, V. La cultura popular y la erotización de las niñas. En: CURRAN, J., MORLEY, D., WALKERDINE, V.: (eds.). Estudios culturales y comunicacin. Anlisis, produccin y consumo cultural de las polticas de identidad y el postmodernismo. Barcelona: Paidós: Barcelona, 1998, p. 481-495.

\section{LAURA TRAFÍ}

es doctora en Bellas Artes con la tesis La interpretacin del arte moderno como produccin narrativa. Una investigacin interdisciplinar desde la historia crtica y la educacin artstica. Actualmente trabaja como formadora de educadores/as en la Facultat de Ciències de I'Educació, Universitat Autònoma de Barcelona y es profesora en el máster de Estudios de la Cultura Visual de la Universitat de Barcelona. Su investigación se focaliza en dos líneas de estudio: Historia crítica, modernidad y estudios de cultura visual, y Comprensión crítica del arte y formación de las identidades docentes e infantiles. Contactar: Facultat de Ciències de I'Educació, Universitat Autònoma de Barcelona, g6/155, 08193 Bellaterra, Cerdanyola del Vallés, España. Email: 'trafilaura@hotmail.com'. 